\title{
Del mito del Narciso a la selfie. Una arqueología de los cuerpos codificados
}

\section{Norberto Leonardo Murolo ${ }^{1}$}

Recibido: 2015-01-08

Enviado a pares: 2015-01-15
Aprobado por pares: 2015-03-15

Aceptado: 2015-03-30

DOI: $10.5294 /$ pacla.2015.18.3.3

Para citar este artículo / To reference this article / Para citar este artigo

Murolo, N. L. (Septiembre de 2015). Del mito del Narciso a la selfie: una arqueología de Ios cuerpos codificados. Palabra Clave, 18(3), 676-700. DOI: 10.5294/pacla.2015.18.3.3

\section{Resumen}

En la contemporaneidad asistimos a la búsqueda por parte de los nuevos medios de sus propias identidades narrativas. Estas vienen acompañadas, generalmente, de novedosos usos de las tecnologías. En este sentido, el universo de las redes sociales virtuales nos propone diferentes modos de contar relatos audiovisuales, además de experimentaciones con el, los videojuegos y diversas formas de transmediación. En ese terreno coexisten narrativas y usos de viejos medios, convergen y se actualizan prácticas de sentido previas que se bautizan con nuevas nominaciones. Las redes sociales virtuales se encuentran insertas en una dinámica narrativa del Yo, propia de Internet. El sujeto de la comunicación —a veces llamado prosumidorse cuenta generalmente a sí mismo, tiene amigos, seguidores y narra la cotidianidad de su vida para ellos. Alrededor de estas dinámicas, la imagen ocupa un lugar central. De allí que se afianzara la fotografía como práctica privilegiada en este espacio.

La selfie - fotografía autotomada - resulta una narrativa propia de las redes sociales virtuales. Sin embargo, en su existencia y genealogía participan otros lenguajes, como el mito, la pintura, la literatura, la fotografía como arte y diversas incorporaciones sociales de las tecnologías. Estos sentidos

1 Universidad Nacional de Quilmes, Argentina.nlmurolo@unq.edu.ar 
son los que nos interesa rastrear desde una perspectiva ensayística asentada en un relacionamiento bibliográfico arqueológico, para desde allí permitir una reflexión filosófica de un fenómeno actual poco explorado, siempre focalizando nuestro interés en el aspecto comunicacional de las dinámicas sociales que se despliegan mediante estos usos de la imagen. ¿Cuáles son los elementos constitutivos de una imagen producto de una fotografía autotomada para ser compartida en Internet? ¿Cuánto de esta relación personal con la propia imagen le pertenece al sujeto natural y cuánto al que se encuentra atravesado por la cultura? ¿A quién se dirige? ¿Qué comunica? ¿Qué le corresponde a la comunicación, como mirada, decir al respecto?

El fenómeno de la selfie es relativamente nuevo, al menos lo suficiente como para no hallarse material académico-científico que trate el tema. El tema le interesa a la prensa en relación con prácticas juveniles novedosas, de allí que existen artículos periodísticos que reflejan el fenómeno sin profundizar demasiado. El presente texto se propone como un racconto de información, historización y punto de partida para la profundización en la investigación y el análisis del fenómeno de la selfie, desde una perspectiva comunicacional.

\section{Palabras clave}

Imagen, fotografía, historia, selfie, lenguaje (Fuente: Tesauro de la Unesco).

\section{The Myth of Narcissus to selfie. An Archaeology of the Coded Bodies}

\section{Abstract}

In the contemporary world we witnessed the search by the new media of their own narrative identities. These are accompanied, generally, to novel uses of technology. In this sense, the universe of virtual social networks proposes different ways of telling visual stories, along with experiments with multimedia, video games and various forms of transmediation. In that area coexist narratives and old uses of media, converge and practices of previous 
sense that are baptized with new nominations. Virtual social networks are embedded in a narrative dynamic of I (self), befitting of the Internet. The subject of communication, - sometimes called prosumer- usually counts oneself, has friends, followers and tells his/her everyday life for them. Around these dynamics, the image is central. Hence photography is held as the privileged practice in this space.

The selfie — self-made photograph — is a narrative of virtual social networks. However, in its existence and genealogy other languages participate, such as myth, painting, literature, photography as art and various social incorporation of the technologies involved. These senses are the ones we want to track from an essay based on an archaeological perspective bibliographic relationships, and from there allow a philosophical reflection of a current phenomenon unexplored, always focusing our interest on the communications aspect of social dynamics that unfold through these uses of the image. What are the constituent elements of a photograph, a product of a self-made image to be shared on the Internet? How much of this personal relationship with the image belongs to the natural subject and how that is crossed by culture? To whom is it addressed? What does it communicate? What does the communication have to say?

The Selfie phenomenon is relatively new, at least not enough to have academic and scientific materials that address the issue. The subject is of interest to the press in connection with new youth practices, hence there are newspaper articles that reflect the phenomenon without going into depth. The current text is proposed as a racconto of information, historicizing and a starting point for deepening research and analysis of the phenomenon of selfie, from a communications perspective.

\section{Keywords}

Image, photography, history, selfie, language (Source: Unesco Thesaurus). 


\section{Do mito do Narciso à selfie. Uma arqueologia dos corpos codificados}

\section{Resumo}

Na contemporaneidade, assistimos à busca por parte dos novos meios de suas próprias identidades narrativas. Estas vêm acompanhadas, geralmente, de inovadores usos das tecnologias. Nesse sentido, o universo das redes sociais virtuais propõe-nos diferentes modos de contar relatos audiovisuais, além de experimentações com a multimídia, com os videogames e com diversas formas de transmediação. Nesse terreno, coexistem narrativas e usos de velhos meios, convergem e atualizam-se práticas de sentido prévias que se batizam com novas denominações. As redes sociais virtuais encontram-se inseridas em uma dinâmica narrativa do Eu, própria da internet. $\mathrm{O}$ sujeito da comunicação —às vezes chamado prosumer - conta geralmente a si mesmo, tem amigos, seguidores e narra a continuidade de sua vida para eles. Ao redor dessas dinâmicas, a imagem ocupa um lugar central. Por isso, a fotografia estabeleceu-se como prática privilegiada nesse espaço.

A selfie - autorretrato - resulta uma narrativa própria das redes sociais virtuais. No entanto, em sua existência e genealogia, participam outras linguagens, como o mito, a pintura, a literatura, a fotografia como arte e diversas incorporações sociais das tecnologias. Esses sentidos são os que nos interessa investigar a partir de uma perspectiva ensaística assentada em um relacionamento bibliográfico arqueológico, para então permitir uma reflexão filosófica de um fenômeno atual pouco explorado, sempre centrando nosso interesse no aspecto comunicacional das dinâmicas sociais que se desdobram mediante esses usos da imagem. Quais são os elementos integrantes de uma imagem produto de um autorretrato para ser compartilhada na internet? Quanto dessa relação pessoal com a própria imagem pertence ao sujeito natural e quanto ao que se encontra atravessado pela cultura? Para quem está dirigido? O que comunica? O que tem a comunicação a dizer a respeito? 
O fenômeno da selfie é relativamente novo, ao menos o suficiente para não se encontrar material acadêmico-científico a seu respeito. $\mathrm{O}$ tema interessa à imprensa com relação a práticas juvenis inovadoras, razão pela qual existem artigos jornalísticos que refletem o fenômeno sem aprofundar demais. O presente texto propõe-se como um racconto de informação, historização e ponto de partida para o aprofundamento na pesquisa e na análise do fenômeno da selfie, a partir de uma perspectiva comunicacional.

\section{Palavras-chave}

Imagem, fotografia, história, selfie, linguagem (Fonte: Tesauro da Unesco). 


\section{Una arqueología de los cuerpos codificados}

Una gramática histórica de la connotación iconográfica tendría,
por tanto, que buscar sus materiales en la pintura, el teatro,
las asociaciones de ideas, las metáforas corrientes, etcétera,
es decir, precisamente en la "cultura".
Roland Barthes, El mensaje fotográfico (1961)

El mito de Narciso es probablemente el primer relato relevante alrededor de la propia imagen. Bello y adorado, Narciso no correspondía amor alguno que le fuera declarado. Cuenta la historia que una ninfa llamada Eco lo amaba con devoción, mientras que, con su gran ego y arrogancia, Narciso la rechazó y ella enloqueció. La ninfa, hundida en una pena que no supo sobrellevar y recluida en una cueva, se redujo a una voz que repetía aquello que los caminantes decían, a modo de sollozo constante hasta el hastío. Por su parte, Narciso fue condenado a amar su propia imagen y a perecer por ello. Un día se acercó al borde de la laguna y vio una bella imagen reflejada; al intentar alcanzarla cayó. En el lugar nació al tiempo la flor que lleva su nombre.

Este mito nos habla de la imagen de uno mismo como engaño, y de allí sienta las bases para pensar los sentidos en la relación que establecemos con esa dimensión del Yo, la cual en diversos usos asume un lugar preponderante. ${ }^{2}$ El mito es un habla, sentenció Roland Barthes (1958), y en un habla siempre se actualiza un lenguaje. El mito se asienta en la legitimidad de la creencia y sirve a una cultura determinada como sendero estereotipado, como formas morales y éticas. Aquel uso disciplinador de los mitos y del arte griego se posicionaba como partícipe de prácticas sociales. La modernidad, también, cuenta con sus propios mitos cimentados en la reiteración, deshistorización y cosificación cultural.

2 La psicología, y puntualmente el psicoanálisis, construye el concepto de narcisismo para describir una perversión. Dice Freud "El término narcisismo procede de la descripción clínica, y fue elegido en 1899 por Paul Näcke para designar aquellos casos en los que individuo toma como objeto sexual su propio cuerpo y lo contempla con agrado, lo acaricia y lo besa, hasta llegar a una completa satisfacción. Llevado a este punto, el narcisismo constituye una perversión que ha acaparado toda la vida sexual del sujeto, cumpliéndose en ella todas las condiciones que nos ha revelado el estudio general de las perversiones" (Freud, 1916). 
Por su parte, otro lenguaje o sistema de representación, el del arte pictórico, empleó y emplea la imagen de uno mismo para denunciar, para estetizar, para dar cuenta de una conciencia de época. Desde el Paleolítico, la representación de las escenas de cacería significaba la recreación del temor por la bestia y la celebración del heroísmo de los guerreros. La imagen era entonces una manera simbólica de elaborar los temores y logros. Con el correr de los siglos, la pintura se fue sofisticando, mediante técnicas y elementos, hasta llegar al estatuto de arte indiscutido que le dio la institucionalización. En este devenir, la práctica del autorretrato obedecía también a cuestiones personales y ligadas al mandato mimético de la pintura: representar la naturaleza. Mediante espejos y talento, los artistas (re)creaban imágenes de sí mismos como obras de arte excelsas presentadas en sociedad en eventos de gala, donde se admiraba su parecido con el autor como índice de majestuosidad y genio.

Algunos pintores forjaron una carrera artística perenne alrededor de la práctica del autorretrato. En el siglo XVII, Rembrandt fue uno de los primeros pintores en desplegar la mayor parte de una obra en este sentido, con casi 90 autorretratos. ${ }^{3}$ Van Gogh realizó 37 autorretratos, donde expresaba sus temores y sensaciones perturbadoras. Por su parte, Frida Kahlo se pintó en la mayoría de sus 192 obras.

Estas obras construidas en diferentes momentos históricos constituyen formas de representación de sus autores, quienes con ellas proponen también una crítica y una forma de mostrarse ante sus inconvenientes personales y ante las problemáticas sociales que los rodean. Ofician así como un arte comprometido con su situación, que nos habla de sus autores como representación de su mirada interpelante, pero también de un estilo de época.

En el terreno del lenguaje narrativo, Oscar Wilde también tematizó la imagen de uno mismo cuando en 1890 publicó El retrato de Dorian Grey en el Lippincott's Magazine. En la novela, el millonario Dorian Grey pacta con el diablo para que sea su retrato el que envejezca y sufra los cambios que su

3 Se cree que la práctica del autorretrato proviene de la antigüedad clásica y otros pintores realizaron autorretratos aislados; sin embargo, mencionamos a los artistas que desplegaron la mayor parte de su obra alrededor de este ejercicio. 
cuerpo ya no experimentaría, pues permanecería siempre joven y bello. Tal fue el punto del deterioro gradual de la pintura que su decisión fue esconderla para que nadie la viera. El propio artista que la creó vio el estado de la obra y, ante su enojo por lo que el millonario había hecho con ella, comenzó una discusión, en la que Dorian Grey lo mató. La obra literaria propone reflexionar sobre el lugar de la propia imagen en las relaciones sociales y las puertas que abre la belleza, en conjunto con la seducción y el poder.

Vernos bellos y controlar la imagen que ven de nosotros se torna entonces un universal. Se trata de un imposible por el cual luchar en todo momento - los círculos sociales que frecuentamos, la moda y el mercado nos proponen eso-, a pesar de saber que es una disputa perdida contra el tiempo. Sostenía Sigmund Freud (1930) en El malestar en la cultura que existen tres elementos que le causan sufrimiento al sujeto social: uno de ellos es el propio cuerpo, "que, condenado a la decadencia y la aniquilación, ni siquiera puede prescindir de los signos de alarma que representan el dolor y la angustia." ${ }^{4}$ Controlar la imagen que los demás ven de nosotros nos posiciona como todopoderosos de alguna dimensión de la construcción, al menos la semiológica, de nosotros mismos.

Por el año 1936 fue Walter Benjamin quien se interesó por reflexionar acerca de una problemática consciente de época: el surgimiento del cine y la fotografía. En "La obra de arte en la época de su reproductibilidad técnica”, Benjamin sostiene que, ante la posibilidad de ser reproducidas, las obras de arte pierden su aura, su "aquí y ahora". En este sentido — y alejado de las posturas apocalípticas de Theodor Adorno y Max Horkheimer en Dialéctica del iluminismo - ${ }^{5}$ no ve en ello una devastación cultural sino un cambio en los esquemas de "percepción sensorial" (nuevos sensorium):

Dentro de grandes espacios históricos de tiempo se modifican, junto con toda la existencia de las colectividades humanas, el modo y la

4 Los otros dos elementos son del mundo exterior, capaz de encarnizarse en nosotros con fuerzas destructoras omnipotentes e implacables; por fin, de las relaciones con otros seres humanos. El sufrimiento que emana de esta última fuente quizá nos sea más doloroso que cualquier otro; tendemos a considerarlo como una adición más o menos gratuita, pese a que bien podría ser un destino tan ineludible como el sufrimiento de distinto origen (Freud, 1930).

5 Adorno y Horkheimer (1970) señalan que la industria cultural se despliega mediante fórmulas probadas y estereotipadas; fabricados en serie, los productos culturales obedecen a una lógica mercantil que clausura la estética y el arte, por lo cual cumplen una función alienante para los sujetos. 
manera de su percepción sensorial. Dichos modo y manera en que esa percepción sensorial se organiza, el medio en el que acontecen, están condicionados no sólo natural sino también históricamente (Benjamin, 2007, p. 153).

La fotografía naciente no era como la conocemos en la actualidad; un ejercicio complejo sería situarnos como seres histórico-sociales actuales en aquel esquema de percepción sensorial que se veía trastocado por la posibilidad de tomar imágenes de lo que hacíamos, de nuestros objetos y de nosotros mismos, imágenes casi mágicas que quedarían disponibles para la posteridad, trascendiéndonos y haciendo posibles los usos políticos de la fotografía y ciertas modificaciones en el estatuto del arte y en la comunicación. Las problemáticas, entonces, giraban en torno tanto al lugar de las masas como receptoras de imágenes, como del lugar del arte mimético ante la fotografía, que ya no tendría como mandato principal copiar la naturaleza, sino que la recortaría y (re)presentaría con sus colores y sus formas sin aparente codificación.

En ese contexto, la fotografía todavía no participaba de un uso doméstico, y transcurrió gran parte del siglo XX para que llegara a hacerlo. Las cámaras, los rollos y los revelados fueron manufacturas de la imagen fija que salieron al mercado, en un principio como consumo profesional y en algunos casos suntuario para quienes pudieran estilizar la práctica como recreativa. La fotografía era testimonial de un evento; como documento demostraba que eso "había sido" y dejaba vislumbrar, como lo hace todo lenguaje, que en potencia era arte, al desplegarse como un sistema de representación que propiciaba la creatividad de quienes maniobraran una cámara.

Para el fin de la construcción semiológica de uno mismo, la imagen es el soporte elegido y la fotografía su forma más ritualizada. La fotografía se trata de un mensaje sin código, sostiene Barthes en 1961, y de ello que su nivel denotativo - el que se pretende objetivo - radica en su mímesis con lo real que representa. Sin embargo, el nivel de la connotación también se manifiesta evidenciando el carácter mítico de la objetividad fotográfica. "Se trata de un sentido secundario cuyo significante consiste en un determinado 'tratamiento' de la imagen bajo la acción del creador y cuyo significado, 
estético o ideológico, remite a determinada 'cultura' de la sociedad que recibe el mensaje" (Barthes, 1986, p. 13).

La fotografía puede entenderse como ícono, es decir que guarda relación de semejanza con el referente; asimismo, como índice, pues guarda una relación de contigüidad con el referente. Sin embargo, debemos reflexionar acerca de la imagen, al igual que de la palabra, como símbolo. Esta codificación podría entenderse desde los parámetros que señalaba Barthes (1986) para pensar la fotografía: trucaje, pose, objetos, fotogenia, esteticismo, sintaxis. Una construcción se encuentra detrás de las imágenes. Estas decisiones, sean propias o de otros gestores de la imagen, recorta una posible manera de mostrar al referente. Allí, los seis elementos de codificación de la imagen son contingentes, intercambiables (paradigmáticos en términos barthesianos), y en cada caso, en cada imagen, podrían haber sido otros. De ello que "su 'objetividad' (esas son las características que el sentido común atribuye a la fotografía), es algo que corre el riesgo de ser mítica, pues de hecho existe una elevada probabilidad (y esto sería ya una hipótesis de trabajo) de que el mensaje fotográfico, o al menos el mensaje de prensa, esté también connotado" (Barthes, 1986, p. 15).

La fotografía como arte tiene muchos nombres y muchos rostros, como el del peruano Martín Chambi o el del francés Henri Cartier-Bresson. ${ }^{6}$ Asimismo, otros destacados fotógrafos como Diane Arbus, Robert Frank y William Klein son conocidos como artistas de renombre. Sin embargo, quien estilizó la fotografía de la imagen de sí misma como arte fue la estadounidense Cindy Sherman. Se trató de una decisión política: girar la cámara hacia sí misma. Con ello, Sherman se convirtió en una de las fotógrafas más respetadas del siglo XX; de hecho, en 2011 expuso su obra en el Museo de Arte Moderno de Nueva York. A pesar de que la mayoría de sus fotografías son imágenes de su cuerpo y su rostro, no se trata de autorretratos. Sherman se utiliza a sí misma como un vehículo para una variedad de temas del mundo moderno: el papel de la mujer, el papel del artista y muchos más, mediante la codificación de su propia imagen. A través de

6 El portal 20minutos.es los sitúa como los mejores fotógrafos de la historia. Recuperado el 6 de diciembre de 2014 de http://listas.20minutos.es/lista/los-mejores-fotografos-de-la-historia-353326/ 
una serie de diferentes obras, Sherman ha planteado difíciles e importantes preguntas sobre el papel y la representación de las mujeres en la sociedad, los medios de comunicación y la naturaleza de la creación del arte.

Más adelante en el tiempo comenzaron a surgir diferentes cámaras y modos de "revelar" esas fotografías, hasta llegar a finales del siglo XX y la posibilidad — muchas veces entendida como una revolución comunicacional - de la digitalización. En el marco de este cambio tecnológico, las cámaras fotográficas fueron bajando sus costos y se diseminaron como propiciadoras de usos domésticos. En ese nuevo esquema de percepción sensorial, la construcción de una propia imagen, que antes se encontraba reservada para la vida presencial — mediante la moda, la vestimenta, la peluquería, el maquillaje y demás accesorios-, ahora también puede tener lugar en el uso amateur y a cualquiera le es posible dedicarle parte del tiempo de ocio a llevarla a cabo para ser retratada en fotografías. Dadas las apropiaciones sociales en este sentido, el mercado nos propone las más diversas cámaras que fotografían con la opción del temporizador (timer), para permitirnos adoptar una posición en la que queremos que nos sea tomada la foto, como también opciones de identificación delas sonrisas o de edición con efectos visuales desde la misma pantalla (display), antes de descargar la foto de la cámara a una computadora o subirla vía conexión inalámbrica a Internet. Las cámaras fotográficas, y los teléfonos móviles, participan entonces de prácticas sociales de la construcción de la imagen de uno mismo.

Finalmente, a principios del siglo XXI nacieron en Internet espacios donde compartir todo tipo de producción comunicacional propia, frases, videos, imágenes y reflexiones: las redes sociales virtuales propician entonces una cultura colaborativa y un escenario del Yo. Como nunca antes, las fotografías recién tomadas pueden llegar en segundos a un público destinatario, y esto cambia cualitativamente el estatuto de la fotografía doméstica. Las dinámicas que surgen con cámaras fotográficas, telefonía móvil y desarrollos de la edición de estas producciones tienen que ver con una perspectiva sociocultural, más que tecnológica, donde los antecedentes que narramos en cuanto a la historia de las representaciones de la propia imagen en la vida cotidiana ofician como genealogía inconsciente de las prácticas actuales. 


\section{La selfie como discurso de las redes sociales virtuales}

La fotografía participa de usos habituales en la configuración de la semiología personal en redes sociales virtuales. La imagen seduce, cuenta con ese halo de encantamiento propio de la publicidad, la televisión y el cine. La imagen es un territorio que mediante la pose, el encuadre, la utilería, la vestimenta, la escenografía y el retoque digital se convierte en gobernable. La imagen digital es un espacio donde los jóvenes se sienten seguros, quien más quien menos tiene una imagen en donde se gusta a sí mismo y la presenta ante los demás en esa copresencia virtual de las redes sociales. Cada uno en su perfil se expone irremediablemente: cede ante los demás mostrándose — no puede no hacerlo-, pero tiene la libertad dentro de la red de elegir el modo de hacerlo. Sostiene Roxana Morduchowicz que "los adolescentes utilizan el verbo 'ver' permanentemente cuando hablan de sus blogs o perfiles. La visibilidad se vuelve un objetivo central para ellos. Aun cuando este deseo de 'verse y ser visto' en realidad no es tampoco exclusivo de los adolescentes" (Morduchowicz, 2012, p. 48). De allí que se creen las más diversas formas comunicacionales y dinámicas de exposición en las redes sociales virtuales.

Existe un nuevo vocablo en inglés que se extendió a los hispanohablantes: selfie ${ }^{7}$, que se utiliza para denominar las fotografías autotomadas. Esta es una práctica social que, a pesar de que su uso es realizado por cualquier corte etario, ve en los jóvenes a sus principales legitimadores.

El nombre selfie se masificó durante la entrega de los Premios Óscar en 2014, cuando la presentadora de televisión estadounidense Ellen DeGeneres $^{8}$ se tomó una fotografía de este estilo con los famosos presentes y la posteó en su cuenta de Twitter. Esa imagen se convirtió en el tuit más compartido de la historia, con 1,7 millones de retuits en una hora. Como

7 Según el diccionario de Oxford, selfie es "Una fotografía que fue tomada por uno mismo; típicamente tomada con un teléfono móvil o una cámara web y compartida vía redes sociales virtuales". "A photograph that one has taken of oneself, typically one taken with a smarthphone or webcam and shared via social media”. Recuperado el 10 de diciembre de 2014 de http://www.oxforddictionaries.com/es/definicion/ingles_americano/selfie

8 Ellen DeGeneres cuenta con 35,3 millones de seguidores en Twitter. Su cuenta: https://twitter.com/TheEllenShow (consultado el 30 de noviembre de 2014). 
metáfora, su genealogía, entonces, data en Hollywood, espacio central de la industria cultural contemporánea.

Otro dato que refuerza la reproducción de la práctica en Argentina es el uso dado a las selfies por el conductor de televisión Marcelo Tinelli ${ }^{9}$ en sus programas de 2014, donde emuló a DeGeneres. Tinelli es uno de los presentadores más vistos de la televisión argentina; desde hace dos décadas ingresa en los hogares con programas en el horario central (prime time) de los canales líderes en audiencias. Su show televisivo incluyó números en vivo, humor, y el segmento "Bailando por un sueño", variante argentina del mundialmente difundido Bailando con las estrellas. El conductor siempre apeló a un público juvenil y adolescente que consumió sus propuestas desde los comienzos. En este sentido, la práctica de la selfie que produce $\mathrm{Ti}$ nelli junto a los participantes de su programa forma parte de un feedback para con los televidentes usuarios de Twitter, quienes retuitean y comentan estas fotografías que el conductor tuitea en vivo desde su programa. Esta sincronización entre la televisión y la red social virtual le granjea retroalimentación con el público y una suerte de sensación de formar parte que las redes sociales virtuales proponen como capital de los televidentes. La televisión, que se encuentra en proceso de digitalización y de estilización de las bondades de este estadio, como por ejemplo la interactividad, emplea, como en el caso de Tinelli, las redes sociales virtuales como canal de retorno a sus propuestas, algo así como un termómetro de la aceptación asentada en las opiniones y comentarios - más allá de los fríos números del rating. En este escenario, la selfie se construye como un producto transmediático que fluye de la pantalla televisiva — desde el otro lado de la pantalla vemos cómo se toma esa selfie, inclusive vemos a Tinelli posteándola desde su teléfono- - y que inmediatamente se puede comentar en Internet desde el sofá de nuestra casa con el teléfono móvil en la mano, lugar material y simbólico que ocupa(ba) el control remoto. La selfie participa en este caso como disparador en la decisión de intervención de los usuarios en el programa de televisión que están viendo.

9 Marcelo Tinelli cuenta con 4,75 millones de seguidores en Twitter. Su cuenta: https://twitter.com/cuervotinelli (consultado el 30 de noviembre de 2014). 
En relación con este fenómeno, Cristina del Pino y Elsa Aguado sostienen que "la 'TV Social' ha llegado, y, como consecuencia y dentro de este contexto interactivo en el que se mueve el nuevo espectador, el my time parece coincidir definitivamente con el prime time, permitiendo vislumbrar una relación simbiótica entre televisión e Internet de la que sin dudas los medios salen fortalecidos" (2012, p. 207).

Por su parte, Henry Jenkins (2010) puntualiza el rol de las audiencias de fanáticos en la construcción de mensajes propios, que de modo colaborativo se proponen como complemento y correlato de las producciones mediáticas de las que son aficionados. Estos piratas de textos - en palabras de Jenkins - se apropian de un discurso mass mediático y lo recrean, reconfiguran, comentan y comparten agregando sus sentidos en este juego polisémico. En este terreno comunicacional, donde se habilita a las audiencias a participar, las redes sociales virtuales juegan un rol de relevancia. En estos casos, la construcción de imágenes sigue siendo una de las maneras más habituales de participar en los perfiles de redes sociales virtuales de los programas televisivos, con el fin de presentarse con rostro como sujetos de la comunicación, sobre todo cuando desde los medios se les solicita que compartan fotografías mostrando sus cotidianidades. ${ }^{10}$

Cabe aclarar que este uso de las fotografías autotomadas ya era habitual entre los jóvenes del modo en que lo describíamos. Sin embargo, como "formato" propio de Internet, como específicamente discurso de las redes sociales virtuales, necesitó de otro medio masivo, de la promoción de celebrities del cine y la televisión, para que fuera conocido.

Hasta hace poco tiempo en Argentina a este tipo de fotografías se lo denominaba "foto flogger", por tratarse de una práctica constitutiva de esta "tribu" urbana de mediados de los 2000. Estos jóvenes realizaban la práctica de la autofotografía para subirla a Internet en sus perfiles de Fotolog. Este espacio proponía mediante un perfil personal postear una fotografía

10 Durante el Mundial de Fútbol de 2014, desde la transmisión de los partidos se instaba a los televidentes a que compartieran sus fotos — al estilo selfie — viendo el partido y festejando los goles. Asimismo, esta práctica se reitera en canales de noticias cuando solicitan a los televidentes sus fotos en medio de una lluvia de granizo, en la playa, en una manifestación o en diferentes eventos sociales. 
por día y comentar las fotografías de los demás usuarios. De este modo se desplegó una incipiente red social virtual que fue apropiada mayormente por jóvenes, quienes "pasaban" (entraban al perfil), "firmaban” (comentaban las fotografías) y pedían que los demás hicieran lo mismo en retribución. La fotografía era exitosa mientras más "firmas" detentaba a sus pies, al tiempo que podía comprarse una membresía que permitía postear y comentar fotografías de manera ilimitada. Este servicio convertía a quien lo compraba en usuario gold. En este juego de apropiación tecnológica, donde no solamente era necesaria la estilización del uso de Fotolog, sino también contar con una cámara fotográfica digital propia, la identidad se completaba con el uso de pantalones chupines de colores, el flequillo sobre la cara y el paso de baile flogger. De esto se deduce que por el lapso de tiempo de la moda, no solo se construyó una práctica de sentido, sino también un modo de estar juntos, una "tribu" urbana, como la nombran algunos autores. Este ritual tiene que ver con la construcción de una imagen propia para ser mostrada en una era de hiperexposición.

Fotolog, y luego Facebook, Twitter, Instagram y demás redes sociales virtuales, se presentan para los jóvenes principalmente como imagen. Los lugares de perfil, portada, álbumes y estados donde poner fotografías resultan entonces espacios privilegiados en la construcción semiológica de uno mismo.

En estos espacios de pura imagen el propio cuerpo es el significante por antonomasia. Los cuerpos participan de un mecanismo de codificación donde la belleza es el referente último alrededor del cual buscar la significación. De allí, en determinados usos juveniles las redes sociales virtuales hacen visible la belleza física como un camino axiológico y deóntico.

El self, en palabras de Mead, refiere al "uno mismo". La mismidad del sujeto se presentaría en la vida cotidiana bajo la forma de su personalidad, su identidad y su carácter objetivados por medio de la comunicación. En estos espacios el self deviene en imagen — tiene que traducirse en lenguaje- $-y$ lo que queda es la forma que cada uno elige para mostrarse. En otras palabras, en estas imágenes se busca alcanzar regímenes de visibilidad 
cercanos al máximo de "interesante", "sexy”, “cool”, "inteligente”, "divertido" y "bello", se pueda.

Los estereotipos de belleza modernos generalmente incluyen las variables de juventud y éxito. Son construidos socialmente con el soporte necesario de los medios de comunicación. Gracias a la publicidad y al star system, sirven de referentes, al tiempo que intentan ser alcanzados como desiderátum. Por supuesto que no la totalidad de los jóvenes que usan redes sociales virtuales participan de este tipo de codificación de su imagen, pero quienes producen una construcción de uno mismo en este sentido lo hacen para convertirse en imagen deseable y popular. En esta producción ocupa un rol necesario la cantidad de amigos, seguidores, "me gusta" y favoritos que se consiguen como medición objetivada de la aceptación alcanzada.

\section{La forma de la selfie como elemento de seducción}

A pesar de tratarse de una práctica novedosa, ya existen poses y espacios, gestos y formas codificadas de mostrarse en una selfie. Dice Jerry Saltz (2014) que, a pesar de que no fue creada por artistas, ni advertida por lo tanto por curadores de arte y fotógrafos, la selfie ya puede considerarse un género. Coincidimos en la apreciación desde la perspectiva de que todo género se asienta en formas reiteradas que coadyuvan a configurarlo como tal. Si hablamos de planos y angulaciones, generalmente la forma de la selfie se asienta en un primer plano, donde la sonrisa es protagonista, y se completa con un ligero ángulo picado, que se acentúa mientras más sean los participantes de la fotografía. Como sostiene Saltz (2014), la selfie se caracteriza por ser una fotografía tomada "a un brazo de distancia"; así se configura el tipo de plano corto posible a ser abarcado por el fotógrafo. Es asiduo por parte de jóvenes, por ejemplo, el hecho de tomarse fotografías ante espejos generalmente en el cuarto de baño de la casa - mirando a la cámara o a los espejos mismos. Las jóvenes generalmente hacen un gesto como enviando un beso al destinatario de la imagen, mientras que la pose se completa con el signo de la V (de la victoria) con los dedos índice y mayor. Esta imagen, impronta moderna de las redes sociales virtuales, es usual y devino en práctica de sentido que denota un saludo y connota sensualidad, belleza, 
ser cool. La imagen participa de la codificación de la pose, juega con la fotogenia, emplea objetos y un espacio determinado en una sintaxis aprendida y reproducida, al tiempo que con el uso de programas como Photoshop o los filtros proporcionados por Instagram evidencia un trucaje con el fin mismo del esteticismo.

El cuerpo es en este procedimiento el significante. Carga con el peso de la codificación que busca gustar. En esta transferencia del mensaje, el "me gusta" facebookero es metáfora y a la vez denotación.

La mayoría de las prácticas sociales participan de un mito. La naturalización de lo cultural, además de oxímoron, es —en el sentido barthesiano- indefectiblemente mítica. La comunicación pertenece al ser natural, quien por necesidad pulsional crea comunidades de sentido, surgidas a la vez de sistemas de representación que a lo largo de la historia se fueron modificando al tiempo que se apropiaba de los lenguajes, materiales y soportes disponibles.

La práctica social con las redes sociales virtuales tiene que ver con la elección de nuestra propia imagen, su codificación y representación. Esta nueva forma de presentarnos es mítica porque atiende a cánones establecidos socialmente sobre lo bello y lo deseable y se atiene a ellos. Estos cánones y estereotipos tiranizan a la imagen moderna, al punto de crear un estándar donde la belleza, universal subjetivo por antonomasia, deviene en objetivable. De ello que los cánones míticos de la belleza se encuentren presentes por trasmutación en la codificación de los cuerpos para Facebook. Estos cuerpos dóciles a las sutiles exigencias de éxito del mercado reproducen el mito, siendo deseables y deseando, con tan poco esfuerzo como el clic en "me gusta".

Exhibirse tiene relación directa con las ganas de agradar. No siempre para gustar en términos amorosos o sensuales, sino para ser elogiado, popular y, de ello, aceptado.

Por su parte, para los jóvenes, los modos de relacionarse con el chico o chica que les gusta mediante tecnologías es una cuestión que ocupa un 
lugar relevante a la hora de los usos de las redes sociales virtuales y la mensajería instantánea. El chat oficia como un espacio de aprendizaje para conquistar. La barrera del desconocimiento del otro en estos casos sirve para animarse a hablar de uno mismo, preguntar, seducir mediante la palabra y la imagen en medio de una construcción de uno mismo que mezcla elementos verdaderos y fantasías.

La definición del diccionario también nos dice que seducir es "Engañar con arte y maña; persuadir suavemente para algo malo", "Atraer físicamente a alguien con el propósito de obtener de él una relación sexual" y "Embargar o cautivar el ánimo" (RAE, 2014).

La idea de engañar no está tan lejana. Un chiste de estos tiempos dice que la fotografía menos agradable de nosotros es la del documento nacional de identidad y que no hay fotografía más bella de nosotros que la de Facebook. Esto tiene que ver con que la fotografía del DNI no la construimos, no tomamos cientos y elegimos una, no posamos como deseamos, no la recortamos, no la editamos. Principalmente, no tiene una intención de seducción. La fotografía de Facebook participa de todas las codificaciones que queramos implementarle y por ello seduce, busca gustar y a veces engañar con arte y maña.

En algunos casos los testimonios de los jóvenes consultados en nuestra investigación parecen advertir que se trata de cumplir con estereotipos que los preceden y los superan. La popularidad estaría ganada al cumplir con formas estipuladas de belleza, generalmente tiranizadas por la moda. Hay jóvenes que hablan sobre este aspecto bajo la noción de "construcción de personaje" y profundizan acerca de las imposiciones sociales y las apropiaciones de mandatos de deber ser estéticos.

Los propios jóvenes reproducen estereotipos discriminadores. Hay casos en que puntualizan directamente en la foto del contacto para aceptarlo como amigo o no.

En cuanto al encuentro, este espacio público virtual propone una facilidad de acceso para enviarle un mensaje al otro que en el cara a cara 
causa vergüenza. Los jóvenes se buscan por Facebook con solamente conocer el nombre de pila y su grupo de pertenencia. De este modo, encontrar a alguien en Facebook no es una tarea complicada, husmear sus fotografías, sus estados y sus informaciones entonces se convierte en una actividad usual que los jóvenes llaman stalkear. De allí que el "encare” sea más fácil. Parece dar menos vergüenza, tanto a varones como a mujeres, agregar a Facebook $y$, al ser aceptado, comenzar a chatear con quien les gusta. En este modo de relacionarse, la imagen ocupa un lugar preponderante.

Se trata de un juego de seducción implícito que no necesita de explicaciones; se propone la amistad de Facebook, se acepta y se charla sabiendo que "se están conociendo". Si no se quiere tener contacto con esa persona, ni siquiera se acepta o se borra a ese contacto; no parece haber una condescendencia propia de la "educación" presencial, esa que decreta que el saludo no se le niega a nadie.

Por otra parte, en el juego de seducción que implica gustar y ser halagado, es interesante conocer una práctica usual entre jóvenes en Facebook llamada "el versus": algo así como una competencia sobre quién es mejor, que se despliega mediante fotografías y con la votación expresada en "me gusta" y en los comentarios.

El caso de la práctica del versus entre jóvenes tiene como protagonista a la imagen. Se elige una imagen propia y una de su contrincante y se les propone a los amigos elegir a quién prefieren, por lo que queda liberada la posibilidad de comentarios. Se trata de una competencia donde la imagen es soporte y unidad de medida de lo bello. Los cuerpos se posicionan para seducir y competir con sus pares. Las disputas por los sentidos en este caso se plantean en un orden intergrupal, donde las jóvenes convocan a sus "seguidores" o "amigos" para salir triunfadoras en la votación. Una práctica mediática "doméstica" que tiene reminiscencias de los realitty shows televisivos, donde el televidente vota por telefonía móvil quién se queda y quién se va del programa. En el marco del versus se despliega entonces una disputa por quién es más bella y más popular. 


\section{A modo de cierre. La dimensión política de la estética}

La fotografía del evento social participa de una construcción para el recuerdo: se toma por ejemplo en cumpleaños, bodas y recepciones. Podríamos llamarla "fotografía recuerdo" por la preponderancia de su carácter indicial, pero sería más propicio utilizar la palabra souvenir porque se trata de un recuerdo objetivado. A su vez, podemos señalar que se construye mediante formas ya probadas y estandarizadas. La mirada a cámara, la sonrisa, el abrazo, sentirse cerca del cumpleañero, de los novios o del graduado. La fotografía social se toma con el protagonista y de allí que oficie de recuerdo. Se trata de una imagen para volver a pasar por ese día. En ese sentido, se trata de un discurso que nunca es presente, es pasado que le habla a un futuro.

Ahora bien, ese tipo de fotografía nació en un momento en el cual la cámara no era de uso doméstico y el profesional de la fotografía era contratado para registrar esos eventos. Cuando la práctica de la fotografía comenzó a ser masiva, además de propiciar otros usos, también se siguió tomando la fotografía social, pero la pudo llevar adelante la familia, los amigos, los allegados y no necesariamente el profesional contratado, salvo que se quisiera tener máxima calidad en esas imágenes. Más adelante, en el marco de la digitalización se hizo posible que tomáramos muchas fotografías hasta encontrar la que más nos gustara. Podemos tomar fotografías de nuestras mascotas, de nuestros objetos, de cualquier evento que encontremos veamos como novedoso o vistoso.

Michel de Oliveira (2014) propone reflexionar acerca de fotografías para lembrar (recordar) y fotografías para esqueçer (olvidar). En este sentido, el punto central de la fotografía tiene que ver con sus usos sociales, los cuales se tornan contingentes y cambiantes según el momento histórico y las dinámicas comunicacionales que integran. El lugar que una fotografía recuerdo ocupa en la biografía familiar no es el mismo que tiene una fotografía de un periódico o, asimismo, las efímeras imágenes que circulan por las redes sociales virtuales. 
En esa contextualización, la selfie participa de una lógica diferente a la de la fotografía del evento social. La definición de selfie incluye ser compartida vía redes sociales virtuales, por lo cual en su constitución se encuentra el carácter de ser vista en el mismo momento que se toma. Los mensajes en las redes sociales virtuales son efímeros, a las pocas horas quedan tapados por otros contenidos y por otros seguimientos, por otros compartimientos, por otros favoritos. Mientras la fotografía del evento social se trata de una fotografía del recuerdo, la selfie es instantánea, es sincrónica, es la fotografía del ahora. Y allí radica su potencia comunicacional, su valor estético y su apuesta política. La fotografía del evento social se construye desde el pasado, para el presente en tanto pasado. La selfie se construye desde el presente para el presente en tanto presente. La fotografía social retrata una situación, un evento que le precede y es necesario recordar. Por su parte, la selfie crea el evento. Comer en McDonald's, encontrarse con alguien por la calle, saludar a un famoso son situaciones cotidianas que la selfie construye como eventos. Decía Barthes que el noúmeno de la fotografía es "esto ha sido". El noúmeno de la selfie sería, entonces, "esto es".

“¿Por qué tomamos selfies?” sería una pregunta por la comunicación. Para representarnos. El sujeto tanto natural como social tiene una necesidad por representarse. Esta necesidad tiene que ver con la experimentación de los propios miedos, con celebrarnos, con controlar el máximo posible la imagen que los demás ven de nosotros. Representarnos es volvernos a presentar dentro de parámetros de construcción comunicacional que controlan de algún modo nuestra incertidumbre.

Como la selfie crea el evento, construye una representación de lo cotidiano que los seres ignotos estamos habilitados a compartir. Los artistas, deportistas y políticos famosos comparten con sus seguidores mediante prácticas sociales y comunicacionales una muestra de lo extraordinario de sus talentos y saberes, ocupan lugares a donde los ignotos no acceden, y mediante las redes sociales virtuales sus seguidores buscan que muestren parte de su cotidianidad. De allí que el hecho de que Madonna cuente que está tomando agua, jugando con sus hijos o cepillándose los dientes sea un mensaje relevante, ritualizado y cargado de sentido comunicacio- 
nal con valor pertinente en el medio. Por otra parte, los ignotos no cuentan con millones de seguidores, y los seguidores que tienen son quienes generalmente comparten su cotidianidad. Para ellos no asume potencia comunicacional que compartan una representación microfísica de lo cotidiano, sino que deben construir mensajes alrededor de lo excepcional que les sucede: viajar a Japón, graduarse, casarse, recibir algún premio. Allí, la selfie como formato propio de estos medios iguala a ignotos y famosos, quienes pueden transmutar en excepcional una porción de lo cotidiano y hacerla publicable.

Por más que el anclaje específico de sus sentidos y la impregnación a lo sincrónico sean característicos de la selfie, se trata sin embargo de un testimonio de época que podría brindarnos muchas pistas acerca del tipo de sociedad en que se inscribe. Si las selfies fueran archivadas, sistematizadas y clasificadas, serían quizás uno de los mayores testimonios culturales fotográficos que una época histórica pudo haber tenido.

La selfie podría tener su genealogía en el mítico encuentro de Narciso en el agua. La imagen de uno mismo por momentos encanta y atrae. El referente se abstrae de sí mismo y se construye como pura retórica. Esta reflexión surge de pensar en términos de lenguajes que producen un habla legitimadora de unas prácticas y censuradora de otras. En cada sociedad los lenguajes fueron y siguen siendo soportes de estos imaginarios. Mediante representaciones, ya sean míticas, pictóricas, literarias, fotográficas o digitales, se crean y postulan estereotipos sociales que se sostienen en las prácticas discursivas.

Los autorretratos de Rembrandt, Van Gogh y Frida Kahlo son famosos como ellos mismos y se presentaron en el escenario artístico como un habla de denuncia, desahogo y expresión. En este contexto, Las Meninas de Velázquez, con su protagonista en escena y mirando al espectador, participa de una estética reproducida por la fotografía grupal contemporánea.

Asimismo, llegada la época de la reproductibilidad técnica, la fotografía como arte tiene en Cindy Sherman a una de sus máximas expositoras. Una 
artista que juega con su propia imagen, con su propio cuerpo experimentando ser otras personas en cada retrato. De allí que la selfie no se encuentre descontextualizada. El sujeto social contemporáneo conoce ejemplos de uso de esta forma de representación.

Ahora bien, ¿cuál es la apuesta estética de la selfie?, y si la hay, ¿cuál es la dimensión política que la constituye? Su estética se asienta en una belleza objetivada propia de los rostros y las sonrisas que en redes sociales virtuales son insumos necesarios. Su dimensión política radica en las decisiones que se toman en la construcción. En la selfie no controlamos otras dimensiones, como si somos buenos, verdaderos o inteligentes, pero proponemos en las estéticas una especie de desiderátum de la imagen del Yo que arroja pistas para leernos.

Entonces, ¿para qué se produce la selfie? Para que los otros nos vean. La idea detrás de ella es ejercer una especie de control sobre lo que los demás ven de nosotros y, por extensión, sobre la imagen mental que se produce en los otros sobre nosotros, siempre intentando estar lo más cercanos al estereotipo de belleza deseable en la sociedad y el momento histórico que atravesamos.

Entonces, ¿para quién se produce la selfie? Para nosotros mismos. Como Narciso, en un primer momento nos enamoramos de nosotros mismos en cada imagen que tomamos de nuestros rostros y cuerpos. Elegimos en cuál nos vemos bien y descartamos las fotografías en las que no, las editamos y controlamos esa presentación en las redes. Por un momento somos tapa de revista.

Los modelos a seguir son propuestos por la sociedad, el star system, los medios de comunicación y la publicidad, y en el medio de prácticas sociales objetivamos esas propuestas como referentes. Mientras el gusto, también moldeado por mecanismos de educación y formación, sigue perteneciendo a un terreno de subjetividad relativa, la belleza estereotipada no participa de este escenario de cierta libertad: allí Brad Pitt y Angelina Jolie son objetivadamente bellos; podemos decir que no nos gustan como hombre 
y como mujer, pero no que no son bellos en el marco de la sociedad histórica en la que nos toca vivir.

La selfie, como producto de las redes sociales virtuales, busca una belleza superficial, pero también índices de pertenencia y la ilusión de superar, por lo tanto, una de las dimensiones que tiranizan la vida en sociedad. La selfie se posiciona en la escena de la comunicación actual como la forma que encontró el sujeto social contemporáneo para sentar las bases de una estética política del Yo en búsqueda táctica de saldar una de las grandes y universales incertidumbres del ser humano: su propia imagen ante los otros y, por extensión, ante el mundo.

\section{Bibliografía}

Barthes, R. (1958). Mitologías. Buenos Aires: Siglo XXI Editores.

Barthes, R. (1986). El mensaje fotográfico. En R. Barthes, Lo obvio y lo obtuso. Imágenes, gestos, voces (pp. 11-27). Buenos Aires: Paidós Ibérica S.A.

Benjamin, W. (2007) (1936). La obra de arte en la época de su reproductibilidad técnica. En W. Benjamin, Conceptos de filosofía de la historia. La Plata: Terramar.

De Olivera, M. (2014). A dicotomia fotográfica: imagens para lembrar; imagens para esquecer. En Intercom - Sociedade Brasileira de Estudos Interdisciplinares da Comunicação XXXVII Congresso Brasileiro de Ciências da Comunicação. Foz do Iguaçu, 2 al 5 de septiembre de 2014. Recuperado el 22 de marzo de 2015 de http:/ / www.intercom.org.br/papers/nacionais/2014/resumos/R9-0563-2.pdf

Del Pino, C. \& Aguado, E. (2012). Redes sociales, social media, distribución y televisión: el nuevo usuario/espectador y los vientos de cambio. En B. León (Coord.), La televisión ante el desafío de Internet. Salamanca: Comunicación Social Ediciones y Publicaciones. 
Freud, S. (1914). Obras completas de Sigmund Freud. Volumen XIV-Trabajos sobre metapsicología, y otras obras (1914-1916), «Contribución a la historia del movimiento psicoanalítico». 2. Introducción del narcisismo (1914). Buenos Aires y Madrid: Amorrortu.

Freud, S. (1930). El malestar en la cultura. Recuperado el 20 de noviembre de 2014 de http://www.dfpd.edu.uy/ifd/rocha/m_apoyo/2/sig_ freud_el_malestar_cult.pdf

Jenkins, H. (2010). Piratas de textos. Fans, cultura participativa y televisión. Madrid: Paidós Comunicación.

Morduchowicz, R. (2012). Los adolescentes y las redes sociales. La construcción de la identidad juvenil en Internet. Buenos Aires: Fondo de Cultura Económica.

Murolo, N. L. (2011). Pantallas, pantallas y más pantallas. Desasosiego en la cultura de la imagen. Revista TELOS, 86, 37-44. Recuperado el 22 de noviembre de 2014 de http://sociedadinformacion.fundacion.telefonica.com/DYC/TELOS/REVISTA/ Perspectivas_86TELOS_PERSPECT_2/seccion=1236\&idioma $=\mathrm{es}$ ES\&id $=2011012709040001$ \&activo $=7$.do

Murolo, N. L. (2014) La construcción semiológica de uno mismo. En N. L. Murolo (ed.)., Hegemonía de los sentidos y usos de las tecnologías de la comunicación por parte de jóvenes del Conurbano Bonaerense Sur. Estudio realizado en Quilmes 2011-2014. Tesis de doctorado en Comunicación. Facultad de Periodismo y Comunicación Social, Universidad Nacional de La Plata. Recuperado el 6 de diciembre de 2014 de http://sedici.unlp.edu.ar/handle/10915/43080

Saltz, J. (2014). Art at arm's length: A history of the selfie. New York Magazine. Recuperado el 22 de marzo de 2015 de http://www.ira.usf. edu/InsideArt/Inside_Art_Enhanced/Inside_Art_Enhanced_ files/6D.Art_at_Arm's_Length_(2014_article).pdf 